\title{
Effect of heat treatment on hardness and wear behavior of weld deposited Co-Cr-Mo alloy
}

\author{
Mantrala Kedar Mallik', Chalamalasetty Srinivasa Rao ${ }^{2}$,
} Vaddi Venkata Sundara Kesava Rao ${ }^{2}$

\author{
${ }^{1}$ Assistant Professor, Vasireddy Venkatadri Institute of Technology, Nambur, Guntur, A.P. India 522508 \\ kedarmallik@gmail.com \\ ${ }^{2}$ Professor, Andhra University College of Engineering (A), Visakhapatnam, A.P. India 533003 \\ csr_auce@yahoo.co.in, kesava9999@gmail.com
}

\begin{abstract}
Metallic materials are generally characterized by the evaluation of hardness and wear resistance of the material at the specified condition. The characterization is necessary for understanding the behavior of the metals, especially alloys, at different conditions. To study the effect of heat treatment on weld deposited Co-Cr-Mo alloy, arc welding process has been used to prepare the samples.Using L9 Orthogonal array of Taguchi method, the samples, in three groups,are heat treated by solution at $1200^{\circ} \mathrm{C}$ for 30,45 and 60 minutes followed by water quenching. Two sets of the samples from each groupare aged at $815^{\circ} \mathrm{C}$ and $830^{\circ} \mathrm{C}$ for 2,4 and 6 hours. All the samples are then tested for their hardness andwear resistances. Microstructure analysis has been carried out from SEM images of the samples. The experiment results reveal that the differences in heat treatment did not influence the grain size of the samples, but the precipitation of carbides varies from sample to sample. The CoCr-Mo alloy samples solutionized at $1200^{\circ} \mathrm{C}$ for 60 minutes have exhibited high hardness $(371.6 \pm 2 \mathrm{Hv})$ and wear resistances. For high hardness and wear resistance, high solution time is required. ANOVA has been carried out to identify the best parameters of heat treatment.
\end{abstract}

Key words: Co-Cr-Mo; welddeposition;solution heat treatment; ageing;microstructure; hardness; wear resistance

\section{INTRODUCTION}

Characterization of a material is done generally by conducting a series of tests on the material like hardness, wear resistance and microstructure analysis. The behavior of Co-Cr-Mo alloy was also analyzed at different conditions of the material samples.

The results of the experiments conducted on Nickel and Carbon free Co-Cr-Mo alloy by applying heat treatment followed by hot forging process reveal that the yield strength of the material decreases with increase in heat treatment temperature and time [1].The optimal results of mechanical properties were obtained at an ageing temperature of $815^{\circ} \mathrm{C}$ for 4 hours and solution at $1120^{\circ} \mathrm{C}$ for 1 hour on as-cast Co-Cr-Mo samples. The mechanical tests showed that an excessive time of dissolution reduces Ultimate Tensile Strength [2]. Dense components of Co-Cr-Mo were fabricated using laser deposition method, by optimizing the process parameters.

The carbide volume fraction and the hardness were comparable with wrought material, but the abrasive wear resistance of laser deposited samples was less [3] .Thephase and shape of the carbide precipitates depend on the carbon content and the type of heat treatment. Shingo Meneta et al have tested ASTM 75 confirming CoCr-Mo alloy samples with four different carbon contents for their microstructures after applying solution heat treatment in the temperature range of $1200^{\circ} \mathrm{C}$ to $1275^{\circ} \mathrm{C}$ for the time periods of 0 to 12 hours. A new $\pi$ phase has been identified in the alloys with carbon content $0.15,0.25$ and 0.35 mass percentage, after heat treatment at high temperature $\left(1275^{\circ} \mathrm{C}\right)$ and low holding times (0.5hour). Complete precipitate dissolution has been achieved in Co-Cr-Mo alloy for the carbon contents less than 0.35 mass percentages [4].The solidification behavior of Co-Cr-Mo alloys was found to be highly influenced by the carbon content when the Mo and Ni contents were within saturation. Addition of boron greatly decreases the solidification temperatures. Intermetallic compounds 
were formed when Mo content or Ni content exceeds certain limit which changes the solidification behavior significantly []ㅡ. $\mathrm{H}$ R Lashgari et al have applied solution heat treatment at $1230^{\circ} \mathrm{C}$ for 3 hours in argon controlled tubular furnace on ASTM F 75 Co-Cr-Mo cast alloy samples, followed by water quenching. All the samples were isothermally aged at $850^{\circ} \mathrm{C}$ for $4,8,16$ and 24 hours. The wear behavior at different loads and microstructures were studied. The results revealed that, the samples aged at 8 hours and 16 hours have exhibited higher wear resistance than the samples aged at 4 hours and 24 hours at the lower loads. The wear resistance of all the samples has increased at higher loads due to the formation of adhesive cobalt oxide compounds [6].

From the literature review it is understood that in all the cases, characterization of the Co-Cr-Mo alloys was concentrated on cast samples. The present paper deals with the study of wear and hardness properties of the weld deposited Co-Cr-Mo samples with the application of heat treatment.The reasons for selecting the weld deposition method are the ease of fabrication of samples, simple equipment, speedy operation and possibility of elimination of oxidation of material during deposition.

\section{EXPERIMENTATION}

Commercially available Co-Cr-Mo alloy (Stellite21, Kennametal Stellite, Goshen, IN, USA) in the form of weld rods has been deposited on a Stainless Steel substrate using Shielded Metal Arc Welding(SMAW) process with a Nihonarc AC300 welding machine (Industrial Welding Corporation, Potrero, Malabon, Metro Manila,1475 Philippines)for a thickness of $5 \mathrm{~mm}$. It is consumable, coated electrode and the parameters of deposition are electrode diameter $(6 \mathrm{~mm})$, input voltage $(230 \mathrm{~V})$, open circuit voltage $(60 \mathrm{~V})$, current $(780 \mathrm{~A})$, speed $(5 \mathrm{~mm} / \mathrm{s})$, arc length $(5 \mathrm{~mm})$ and shielding gas (Argon - as an extra measure, other than flux). Constant weld distance and speed are maintained between the deposit and weld electrode, in order to ensure uniform deposition of the material. The deposition process continued layer by layer, until the desired thickness of 5mm is achieved. No external pressure is applied on the deposits during the process. The composition of the material is shown in Table 1.

Table 1: Composition of Co-Cr-Mo alloy in weight \%.

\begin{tabular}{c|c|c|c|c|c|c|c|c|c|c|c}
\hline Co & Cr & Mo & Fe & C & S & B & Mn & Ni & P & Si & W \\
\hline Bal & 27.6 & 5.6 & 1.4 & 0.2 & 0.003 & 0.002 & 0.6 & 2.74 & 0.004 & 1.7 & 0.2 \\
\hline
\end{tabular}

After completing deposition the steel plate is machined off and the Co-Cr-Mo plate is cut into small pieces of size $15 \mathrm{~mm}$ square, using abrasive cutter. The samples aredivided into three groups and subjected to solution heat treatment at $1200^{\circ} \mathrm{C}$ for 30,45 and 60 minutes followed by water quenching. Each group of the samples is divided into three sets. Using L9 orthogonal array of Taguchi method, two sets of samples from each group are aged at $815^{\circ} \mathrm{C}$ and $830^{\circ} \mathrm{C}$ for 2,4 and 6 hours. The remaining samples are left un-aged(Table 2). Total heat treatment has been carried out in argon gas controlled atmosphere to avoid oxidation of the material at elevated temperatures.

Table 2: L9 Orthogonal array of heat treatment

\begin{tabular}{c|c|c|c|c}
\hline SI. No. & SAMPLE NO. & $\begin{array}{c}\text { SOLUTION TREATMENT TIME } \\
(\mathbf{m i n})\end{array}$ & $\begin{array}{c}\text { AGEING TEMPERATURE } \\
{ }^{\circ} \mathbf{C}\end{array}$ & $\begin{array}{c}\text { AGEING TIME } \\
\text { (HOURS) }\end{array}$ \\
\hline 1 & W1 & 30 & \multicolumn{2}{c}{ No Ageing } \\
\hline 2 & W2 & 30 & 815 & 4 \\
\hline 3 & W3 & 30 & 830 & 6 \\
\hline 4 & W4 & 45 & \multicolumn{2}{|c}{ No Ageing } \\
\hline 5 & W5 & 45 & 815 & 6 \\
\hline 6 & W6 & 45 & \multicolumn{2}{c}{ No Ageing } \\
\hline 7 & W7 & 60 & 815 & 2 \\
\hline 8 & W8 & 60 & 830 & 4 \\
\hline
\end{tabular}

Standard method of polishing withabrasive papers from grit size 200 to 1200 is used for preparing samples for testing. Alumina powder of particle size $10 \mu \mathrm{m}$ has been used forfurther polishing on a single disc polishing machine to obtain mirror finish of the deposits.

One set of the samples are etched electrochemically at $5 \mathrm{~V}$ in $5 \%$ aqua solution of $\mathrm{HCl}$ for 10 sec. The etched samples are used for microstructure analysis from Scanning Electron Microscope (SEM) images. One set of the samples are then tested for their hardness using Vickers micro hardness testing machine (MMT X7 MATSUZAWA) as per ASTM E384-10, at a load of 200g for 20sec.Ten readings are recorded on each 
sample.Wear resistance tests are conducted on another set of the samples using Pin on disc tribometer (Ducom, Bengaluru, India) at two different loads - $10 \mathrm{~N}$ and $20 \mathrm{~N}$. The samples are used as pins and a circular plate of EN31 stainless steel is used as disc. All the wear resistance tests are conducted under dry wear, metal to metal contact conditions for one kilometer run.Thelinear velocity of the run iskept constant. When the track diameter is changed, the angular velocity (rpm) of the machine is adjusted accordingly to maintain constant linear velocity. The leftover particles may cause scars on the polished surface and to eliminate the same, the surface of the disc is cleaned with Acetone after every run. Fivereadings are recorded with each condition of testing. The wear rate is expressed as material loss in $\mathrm{g} / \mathrm{Nm}$. Grey Relational Analysis has been carried out to identify the combined effect of two different loads.

\section{RESULTS}

The SEM images of the weld deposited Co-Cr-Mo alloy samples after heat treatment are shown in Fig. 1. The corresponding hardness test results shown in Table 3 reveal that there is a considerable effect of heat treatment on Co-Cr-Mo alloy samples fabricated with weld deposition.
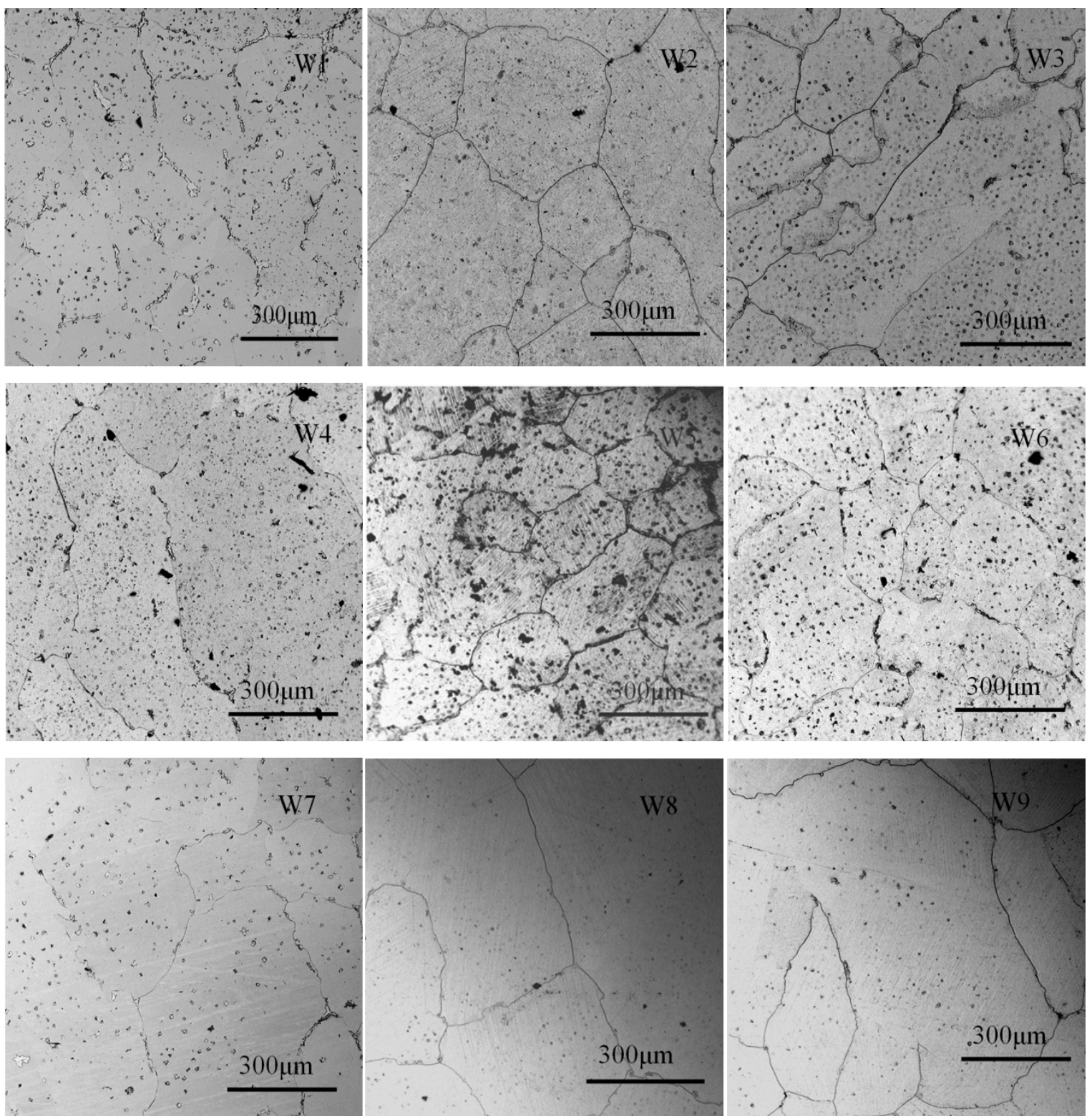

Figure 1: SEM images of microstructure of weld deposited and heat treated samples W1 to W9. 
The samples solutionized at $1200^{\circ} \mathrm{C}$, for 60 minutes and quenched, without ageing (W7) have shown highest hardness values $(371.6 \pm 2 \mathrm{Hv})$ and the samples solutionized for 45 minutes and aged for 6 hours at $815^{\circ} \mathrm{C}$ (W5) have exhibited lowest hardness $(332.1 \pm 7 \mathrm{Hv})$. But still considerable increase in hardness of all the samples has been observed when compared with the samples that are not subjected to heat treatment $(316.5 \pm 3 \mathrm{Hv})$.

Table 3: Hardness Test Results

Sl. No. $\quad$ SAMPLE NO. HARDNESS (Hv)

\begin{tabular}{c|c|c}
\hline 1 & W1 & $348.7 \pm 2$ \\
\hline 2 & W2 & $342.5 \pm 3$ \\
\hline 3 & W3 & $349.6 \pm 2$ \\
\hline 4 & W4 & $351.8 \pm 5$ \\
\hline 5 & W5 & $332.1 \pm 7$ \\
\hline 6 & W6 & $365.7 \pm 3$ \\
\hline 7 & W7 & $371.6 \pm 2$ \\
\hline 8 & W8 & $352.4 \pm 5$ \\
\hline 9 & W9 & $316.5 \pm 4$ \\
\hline 10 & Without Heat treatment &
\end{tabular}

Also the Table 3reveals that all the samples solutionized for 60minutes and aged for 0 or 2 hours have exhibited high hardness. The Analysis of Variance (ANOVA) carried out on the results (Fig. 2) is also in agreement with the same.

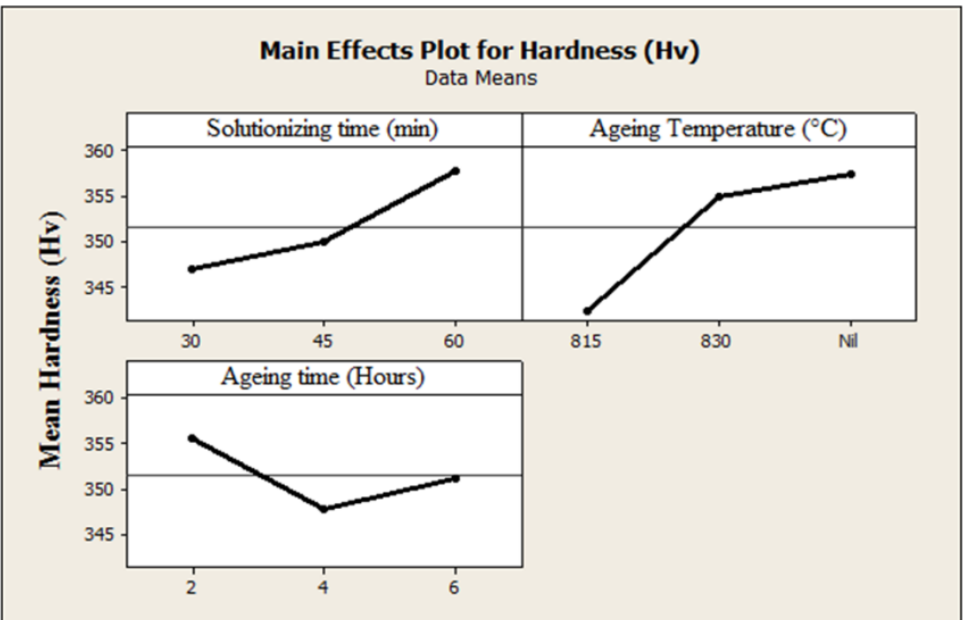

Figure 2: Main effects plot of the heat treatment parameters determined with ANOVA

Table 4: Results of Wear Resistance test and Grey analysis

\begin{tabular}{c|c|c|c|c}
\hline \multirow{2}{*}{ SAMPLE NO. } & \multicolumn{2}{|c|}{ WEAR RATE (G/NM) } & \multirow{2}{*}{ GRADE } & \multirow{2}{*}{ ORDER } \\
\cline { 2 - 3 } & $10 \mathrm{~N}$ & $20 \mathrm{~N}$ & & \multirow{2}{*}{3} \\
\hline $\mathrm{W} 1$ & $1.2 \mathrm{E}-07$ & $1.5 \mathrm{E}-07$ & 0.358215 & 7 \\
\hline W2 & $3.6 \mathrm{E}-07$ & $3.0 \mathrm{E}-07$ & 0.848485 & 4 \\
\hline W3 & $2.1 \mathrm{E}-07$ & $2.3 \mathrm{E}-07$ & 0.476824 & 2 \\
\hline W4 & $1.1 \mathrm{E}-07$ & $1.5 \mathrm{E}-07$ & 0.353592 & 9 \\
\hline W5 & $3.4 \mathrm{E}-07$ & $3.5 \mathrm{E}-07$ & 0.933333 & 5 \\
\hline W6 & $2.5 \mathrm{E}-07$ & $2.5 \mathrm{E}-07$ & 0.538275 & 1 \\
\hline W7 & $1.0 \mathrm{E}-07$ & $1.2 \mathrm{E}-07$ & 0.333333 & 8 \\
\hline W8 & $3.3 \mathrm{E}-07$ & $3.5 \mathrm{E}-07$ & 0.906250 & 6 \\
\hline W9 & $2.9 \mathrm{E}-07$ & $2.5 \mathrm{E}-07$ & 0.592442 &
\end{tabular}


The wear resistance test results are shown in Table 4. The sample W7 has exhibited lowest wear rate among the samples tested, at both $10 \mathrm{~N}$ and $20 \mathrm{~N}$ load. The sample W2 has exhibited high wear rate at $10 \mathrm{~N}$ load and the samples W5 and W8 at 20N load. To identify the best sample for high wear resistance from the combination of $10 \mathrm{~N}$ and $20 \mathrm{~N}$ loads the results are analyzed by using Grey Relational Analysis. To convert the multivariate problems into single response the Grey Relational Analysis is used.The results have shown W7 to be the high wear resistant and W5 to be the lowest. Evidently, the samples which are solutionized for 60minutes but not aged have exhibited high hardness and wear resistance.

\section{DISCUSSION}

When the metal alloys are subjected to heat treatment, the carbides formed during deposition may change their form or get dissolved into the metal matrix. From literature it has been identified that in Co-Cr-Mo alloys, the $\mathrm{M}_{23} \mathrm{C}_{6}$ carbides are formed in cobalt matrixduring deposition where $\mathrm{M}$ can be Chromium or Molybdenum. After solution heat treatment, these $\mathrm{M}_{23} \mathrm{C}_{6}$ carbides get converted as $\mathrm{M}_{7} \mathrm{C}_{3}$ carbides, mostly [2]].All the samples clearly exhibit the precipitation of the carbides along the grain boundaries as well as within the grains. The grain size is almost same in all the samples. However, the samples heat treated with solutionizing for 60min have exhibited coarse grains than the samples heat treated for $45 \mathrm{~min}$ and $30 \mathrm{~min}$. Probably this is due to the availability of sufficient timeat elevated temperature, for grain growth. Note worthy that the grain sizes are also not uniform throughout the image of any sample. Evidently, differences in ageing heat treatment does not influence the grain size of the material, but clear and specific boundaries are formed in the samples aged for 4 hours or more, than the samples that are not aged.

Thesize and quantity of the carbides precipitated vary among the samples tested. It is observed that the size and quantity of the carbides decrease with increase in solution time (W1, W2, W3 to W7, W8, W9) whereas increase with increase with ageing temperature (W2, W5, W8 to W3, W6, W9) and ageing time (W2, W8 to W3, W9). From Fig. 2, the influence of ageing temperature is more than the ageing time and therefore the quantity of carbides does not decrease with increase in ageing time in samples W5 and W6. The carbides are completely dissolved in the cobalt matrix during solutionizing when the solution time is high due to more diffusion. But due to decrease in solid solubility of carbides in cobalt matrix, the carbide precipitation increased with increase in ageing temperature and time.Taking the literature survey into consideration, the carbides are estimated to be Chromium carbides $\left(\mathrm{M}_{23} \mathrm{C}_{6}\right.$ or $\left.\mathrm{Cr}_{7} \mathrm{C}_{3}\right)$. These chromium carbides cause high hardness and wear resistance to the material. Also, as the samples are repeatedly subjected to melting and solidification during weld deposition, the ageing process could not show much influence on hardness and wear resistance. Therefore, the solution treatment at $1200^{\circ} \mathrm{C}$ applied on Co-Cr-Mo alloy samples is in favor of the properties studied but still the hardness is not compatible with wrought material, whereas the wear resistance is at par with as cast material.

\section{CONCLUSIONS}

The conclusions drawn from the experiments conducted on weld deposited and heat treated Co-Cr-Mo alloy are as follows.

The hardness and wear resistance of the Co-Cr-Mo samples has been improved by heat treatment.

$>$ The samplessolutionized at $1200^{\circ} \mathrm{C}$, for 60 minutes and quenched, without ageing have exhibited high wear resistance $(1.0 \mathrm{E}-07 \mathrm{~g} / \mathrm{Nm}$ at $10 \mathrm{~N}$ and $1.2 \mathrm{E}-07 \mathrm{~g} / \mathrm{Nm}$ at $20 \mathrm{~N}$ load) and hardness (371.6 $\pm 2 \mathrm{Hv})$.

$>$ The size and quantity of carbides precipitated increase with increase in solution time and decrease with increase in ageing temperature and/or ageing time.

$>$ Due to repeated heating and meltingduring deposition of the samples, theageing treatment carried out on the solutionized Co-Cr-Mo alloy samples has not shown much effect on hardness and wear properties.

\section{BIBILIOGRAPHY}

[1] LEE, S.-H.,TAKAHASHI, E., NOMURA, N., et al., "Effect of Heat Treatment on Microstructure and Mechanical Properties of Ni- and C-Free Co-Cr-Mo Alloys for Medical Applications", Materials Transactions, v. 46, n. 8, 2005, pp. 1790-1793

[2] GIL, Y. B., JUAREZ-HERNANDEZ, A., PEREZ-UNZUETA, A., et al, "Influence of heat treatments on mechanical properties of a biocompatility alloy ASTM F75", Revista Mexicana De Fisica, v. 55, n.1, 
pp.1-5, 2009.

[3] RAM, G. D. J., ESPLIN, C. K., STUCKER, B. E.., "Microstructure and wear properties of LENS deposited medical grade CoCrMo", J Mater Sci: Mater Med , v.19, pp. 2105-2111, 2008.

[4] MINETA, S., NAMBA, S., YONEDA, T., et al., "Carbide Formation and Dissolution in Biomedical Co-Cr-Mo Alloys with Different Carbon Contents during Solution Treatment", Metallurgical and materials transactions A, v. 41A, 2129-2138, 2010.

[5] LIU, R., Xi, S. Q., KAPOOR, S., et al., "Investigation of solidification behavior and associate microstructures of Co-Cr-W and Co-Cr-Mo alloy systems using DSC technique", J. Mater Sci. ,v. 45, pp.6225-6234, 2010.

[6] LASHGARI, H. R., ZANGENEH , S., KETABCHI, M., "Isothermal aging effect on the microstructure and dry sliding wear behavior of Co-28Cr-5Mo-0.3C alloy", J. Mater Sci, v. 46, pp.7262-7274, 2011. 